Journal of Telenursing (JOTING)

Volume 1, Nomor 1, Juni 2019

e-ISSN : 2684-8988

p-ISSN : 2684-8996

DOI: https://doi.org/10.31539/joting.v1i1.499

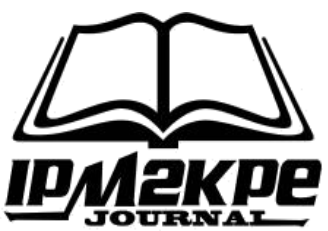

\title{
PENGARUH PUASA RAMADHAN TERHADAP KADAR GULA DARAH PADA PASIEN DIABETES MELLITUS TIPE II
}

\author{
Riandi Alfin ${ }^{1}$, Busjra ${ }^{2}$, Rohman Azzam ${ }^{3}$ \\ Akademi Keperawatan Rumah Sakit Erafina Purwakarta ${ }^{1}$ \\ Universitas Muhammadiyah Jakarta ${ }^{2,3}$ \\ Riandialfin@yahoo.co.id ${ }^{1}$
}

\begin{abstract}
ABSTRAK
Penelitian ini bertujuan untuk mengetahui pengaruh Puasa Ramadhan terhadap kadar gula darah pada penderita diabetes di Puskesmas Kota Purwakarta Jawa Barat. Desain penelitian ini menggunakan quasi eksperimen pre and post test with control group. Hasil penelitian ini menggunakan uji T-Independen puasa perbedaan kadar gula darah setelah puasa ramadhan pada kelompok kontrol dan kelompok intervensi didapatkan nilai $\mathrm{p}=$ $0,039<\alpha=0,05$. Artinya adalah hasil penelitian ini menunjukan adanya pengaruh puasa ramadhan terhadap kadar gula darah pada pasien diabetes mellitus tipe II di Puskesmas Kota Purwakarta. Simpulan, manjalankan Puasa pada bulan Ramadhan dapat dijadikan sebagai metode alternatif diet yang memiliki manfaat positif jika dijalankan oleh penderita Diabetes mellitus tipe II yakni dapat menurunkan gula darah agar lebih stabil.
\end{abstract}

Kata Kunci : Diabetes Mellitus Tipe II, Kadar Gula Darah, Puasa Ramadhan

\section{ABSTRACT}

This study aims to determine the effect of Ramadan fasting on blood sugar levels in diabetics in Purwakarta City Health Center, West Java. The research design used a quasi-experimental pre and post test with control group. The results of this study using the T-Independent test of fasting differences in blood sugar levels after Ramadan fasting in the control group and the intervention group obtained $p$ value $=0.039<\alpha=0.05$. This means that the results of this study indicate the effect of Ramadan fasting on blood sugar levels in patients with type II diabetes mellitus at Puskesmas Kota Purwakarta. In conclusion, carrying out fasting in the month of Ramadan can be used as an alternative diet method that has positive benefits if it is carried out by people with type II diabetes mellitus, which can lower blood sugar to make it more stable.

Keywords: Type II Diabetes Mellitus, Blood Sugar Levels, Ramadan Fasting 


\section{PENDAHULUAN}

Saat ini DM menjadi masalah besar yang terus tumbuh, hal ini dibuktikan dengan laporan dari International Diabetes Federations (IDF) menyatakan prevalensi orang mempunyai penyakit DM didunia pada tahun 2017 adalah 425 juta penduduk dan IDF memperkirakan akan meningkat menjadi 629 juta penduduk pada tahun 2045. Jumlah penderita diabetes diperkirakan pada usia 20-79 orang (United Nations Population Division IDF, 2017). Angka kejadian diabetes di Fasific Barat menempati urutan pertama versi IDF. Orang yang memiliki penyakit DM mencapai 158,757 juta orang. Hal ini merupakan kasus serius yang harus diperhatikan. Indonesia termasuk kedalam negara yang berada di Fasific Barat (IDF Atlas, 2017).

Indonesia menempati posisi ke-6 negara dengan populasi orang Diabetes terbanyak diseluruh dunia dengan angka 10,267,1 juta orang DM (IDF Atlas, 2017). Sekitar 5,1 juta orang yang berusia di antara 20-79 tahun meninggal akibat DM pada tahun 2013 (IDF, 2013). Sedangkan menurut Riskesdas pada 2013, penderita diabetes menyumbangkan 4,2\% kematian terhadap usia (15-44 tahun) diperkotaan dan menjadikan angka kematian nomer ke- 2 pada kelompok usia (45-54 tahun) di perkotaan dengan persentase 14,7\% pada tahun 2007.

Selain itu, menurut Kementerian Kesehatan Republik Indonesia DM menempati urutan angka kematian tertinggi ke-6 di daerah perdesaan dengan persentase 5,8\% pada tahun 2013 (Kemenkes RI, 2013). DM Tipe II merupakan type yang paling banyak ditemui dan angka prevalensinya selalu meningkat di setiap negara (IDF, 2013). Angka kejadian diabetes di Puskesmas Kota Purwakarta berjumlah 1420 orang Pada tahun 2015. Kejadian ini merupakan angka tejadian terbesar ke-2 di Kota Purwakarta. Kejadian diabetes selalu terjadi kenaikan setiap tahunnya yang diakibatkan oleh kurangnya kesadaran masayarakat untuk menjaga kesehatannya.

DM merupakan penyakit degeneratif yang dicirikan dengan ketidak mampuan karbo untuk bermetabolisme, lipid, \& protin sehingga mengacu kepada kondisi peningkatan gula darah (Black \& Hawk, 2014). Penyakit diabetes juga diakibatkan oleh kerusakan metabolisme karbohidrat yang dikarenakan oleh kurangnya atau ketidakadaan insulin hormon dari sel beta, atau akibat gangguan fungsi dari insuln (Sutedjo, 2010).

ketidaknyamanan sebagai tanda timbulnya komplikasi. Penyakit DM sulit disembuhkan melainkan dapat dikendalikan melalui pengelolaan diabetes melitus. Berdasarkan Tim Konsensus Pengelolaan \& Pencegahan DM type II Indonesia tahun 2011 terdapat 4 pillar cara penanggulangan diabetes melitus, diantaranya: Edukasi, Terapi Nutrisi, Latihan fisik, dan Farmakologis. Dalam terapi Nutrisi, penderita diabetes dapat mengontrol asupan makanannya dengan cara berpuasa (PERKENI, 2015).

Puasa dalam arti bahasa ialah menahan. Dalam islam puasa adalah suatu kegiatan/aktivitas beribadah kepada Sang Pencipta dengan menahan diri dari makanan, minuman, hawa nafsu, dan kegiatan-kegiatan lain sejak terbit matahari atau fajar. Puasa dapat menetralkan racun dan zat yang tertimbun pada seluran cerna, organ ginjal, dan organ lainnya yang disebabkan oleh bahan pengawet, larutan pewarna, pemanis buatan, asap rokok, yang menumpuk selama bertahun-tahun (Albiby dalam Liza, 2009).

Salah satu puasa yang wajib dijalankan oleh umat islam tak terkecuali penderita DM yaitu puasa Ramadhan. Penderita DM pun mempunyai kewajiban berpuasa selama 13 jam dalam 1 bulan penuh untuk memperkaya kehidupan sepiritualnya. Puasa selama Ramadan merupakan metode pengendalian diet yang dilakukan oleh penderita DM. 
Selama berpuasa penderita DM mempunyai jadwal makan yang lebih terpola yaitu dua porsi besar pada saat sahur dan berbuka puasa (Yosephine, 2002).

Menurut PERKENI 2015 pada seseorang berpuasa, kadar glukosa darah akan turun sehingga menyebabkan penurunan sekresi insulin, yang kemudian mengakibatkan peningkatan kerja dari hormon kontra insulin, yakni glukagon dan katekolamin yang menghasilkan pemecahan glikogen. Setelah beberapa jam berpuasa, cadangan glikogen akan mulai berkurang. Akibat dari berkurangnya insulin dalam sirkulasi inilah akan menimbulkan pelepasan asam lipid. Asam lemak bisa dipecah untuk menghasilkan energy serta keton. Keton iyalah senyawa yang tidak dapat dilihat dan dapat masuk kedalam aliran darah dan dapat menjadikan sumber energy banyak otot dan pada jaringan tubuh lainnya (Smeltzer \& Bare, 2010).

Beberapa penelitian telah dilakukan oleh American Diabetes Association Scientific Session yang berkaitan dengan puasa telah mendapatkan hasil tentang manfaat puasa dan kesehatan tubuh memberikan efek yang baik, termasuk masalah kesehatan seperti diabetes tipe II. seseorang yang mengalami gula darah yang tinggi krois bisa menjauhi pada risiko terjadinya komplikasi dengan cara melakukan puasa secara bertahap untuk menstabilkan kadar gula darah pada tubuh. Sedangkan riset yang dilaksanakan Bener \& Yousafzai (2014) memperlihatkan bahwwa kadar glukosa darah pada penderita diabetes melitus yang melakukan puasa selama bulan Ramadhan (1 bulan) mengalami penurunan secara signifikan dibandingkan dengan sebelum Ramadhan

Dari hasil studi pendahuluan yang dilakukan oleh peneliti pada 2 minggu sebelum memasuki bulan ramadhan. diperoleh 5 orang yang menderita diabetes tipe II di Puskesmas Kota Purwakarta yang mempunyai kebiasaan untuk menjalani puasa sunnah senin kamis serta 5 orang yang hanya menjalankan terapi perawatan/pengobatan. Dari hasil pemeriksaan sebelum berpuasa didapatkan hasil rata-rata gula darah 138,8 mg/dL pada yang melakukan puasa sunnah senin kamis dan $124,8 \mathrm{mg} / \mathrm{dL}$ pada yang tidak berpuasa. lalu hasil pemeriksaan setelah berpuasa didapatkan hasil rata-rata 123,6 $\mathrm{mg} / \mathrm{dL}$ pada kelompok yg berpuasa senin kamis dan $126,8 \mathrm{mg} / \mathrm{dL}$ hasil yang tidak menjalankan puasa senin kamis. Puasa dapat memberikan pengaruh yang baik terhadap gula darah dengan hasil penurunan sebanyak $16 \mathrm{mg} / \mathrm{dL}$.

Dilihat dari hasil riset sebelum-sebelumnyanya peneliti sangat tertarik untuk melakukan penelitian terkait tentang pengaruh puasa Ramadhan. Penelitian ini berbeda dengan penelitian sebelumnya, peneliti ingin mengetahui pengaruh puasa Ramadhan terhadap kadar gula darah pada klien dengan DM type II pada kelompok intervensi (menjalani puasa ramadan) dan kelompok kontol (tidak berpuasa) di Puskesmas Kota Purwakarta, Jawa Barat.

\section{METODE PENELITIAN}

Jenis penelitian yang digunakan adalah penelitian kuantitatif berjenis Quasi Experiment dengan desain rancangan Pretest-postest with control group design. Peneliti membandingkan pengaruh puasa ramadhan terhadap kadar gula darah antara kelompok intervensi dan kelompok kontrol. Kelompok intervensi yaitu responden yang mendapatkan perlakuan puasa Ramadhan dan terapi perawatan standar dari puskesmas, sedangkan kelompok kontrol hanya mendapatkan terapi perawatan standar dari Puskesmas saja. Alat penelitian lain yang digunakan adalah alat tulis, lembar observasi dan glukometer. 
Sampel penelitian diambil dengan menggunakan teknik purposive sampling yaitu memilih beberapa informan sesuai dengan kriteria-kriteria. Jumlah responden yang perpartisipasi dalam penelitian ini yakni 18 responden dalam masing-masing kelompok.

Pengambilan data pada responden dilakukan pada responden yang bersedia mendandatangani informed concent. Sebelum menjalankan intervensi puasa ramadhan peneliti melakukan pretest dengan memeriksaan kadar gula darah puasa responden disertai penjelasan bagaimana persiapan penelitian. Peneliti meminta responden untuk berpuasa ramadan selama 1 bulan penuh disertai dengan terapi perawatan standar yang dianjurkan puskesmas.Peneliti rutin melakukan pemeriksaan gula darah puasa setiap minggunya untuk meminimalisasi terjadinya komplikasi.Setelah melakukan intervensi puasa ramadhan 1 bulan, peneliti melakukan posttest pemeriksaan kadar gula darah setelah melaksanakan puasa 1 bulan pada responden.

Semua intervensi dan hasil pengukuran yang dilakukan peneliti dengan menggunakan glucometer dicatat langsung dilembar observasi dan lembar pelaksanaan. Dari data yang sudah didapatkan kemudian diolah kedalam matrik pengumpulan data yang sebelumnya telah dibuat peneliti. Data yang sudah terkumpul dianalisis dalam bentuk univariat dan bivariat. Analisis univariat hasil penellitian tersaji dalam bentuk table distribusi frekuensi dan table silang untuk analisis bivariate, uji statistic yang digunakan pada penelitian ini adalah uji paired t tes atau defenden sampel $\mathrm{T}$ - tes dengan $\mathrm{p}$ value $<0.05$.

\section{HASIL PENELITIAN Analisis Univariat}

Tabel. 1

Distribusi Frekuensi Responden Berdasarkan Karakteristik Umur ( $\mathrm{n}=36)$

\begin{tabular}{ccccc}
\hline Variabel & Rata-rata & SD & N & Min-Maks \\
\hline Intervensi & 63.67 & 8.47 & 18 & $47-80$ \\
Kontrol & 60.28 & 7.99 & 18 & $48-75$ \\
\hline
\end{tabular}

(sumber data primer tahun 2018)

Berdasarkan tabel 1 didapatkan rata-rata umur kelompok intervensi $(63,67 \pm 8,47)$, sedangkan pada kelompok kontrol $(60,28 \pm 7,99)$. Rentang umur pada penelitian ini berada pada 47 yahun sampai dengan 80 tahun.

Tabel. 2

Distribusi Frekuensi Responden Berdasarkan Karakteristik Jenis Kelamin, Pendidikan, Konsumsi obat $(n=36)$

\begin{tabular}{|c|c|c|c|c|c|c|}
\hline \multirow[b]{2}{*}{ Variabel } & \multicolumn{2}{|c|}{ Kelompok Intervensi } & \multicolumn{2}{|c|}{ Kelompok kontrol } & \multicolumn{2}{|c|}{ Total } \\
\hline & Frekuensi & $\begin{array}{c}\text { Persentase } \\
(\%)\end{array}$ & Frekuensi & $\begin{array}{c}\text { Persentase } \\
(\%)\end{array}$ & $\mathrm{F}$ & $\%$ \\
\hline Jenis Kelamin & & & & & & \\
\hline 1. Laki-laki & 5 & $45.5 \%$ & 6 & $54.5 \%$ & 11 & 30,56 \\
\hline 2. Perempuan & 13 & $52 \%$ & 12 & $48 \%$ & 25 & 69,44 \\
\hline Pendidikan & & & & & & \\
\hline 1. SMP & 4 & $40.0 \%$ & 6 & $60.0 \%$ & 10 & 27,78 \\
\hline 2. SMA & 11 & $55.0 \%$ & 9 & $45.0 \%$ & 20 & 55,56 \\
\hline 3. PT & 3 & $50.0 \%$ & 3 & $50.0 \%$ & 6 & 16,67 \\
\hline
\end{tabular}




\begin{tabular}{|c|c|c|c|c|c|c|}
\hline Konsumsi obat & 18 & $50 \%$ & 18 & $50 \%$ & 36 & 100 \\
\hline 1. Obat $\mathrm{OHO}$ & 0 & $0 \%$ & 0 & $0 \%$ & 0 & 0 \\
\hline 2. Obat insulin & & & & & & \\
\hline $\begin{array}{l}\text { 3. Obat insulin } \\
\text { dan } \mathrm{OHO}\end{array}$ & 0 & $0 \%$ & 0 & $0 \%$ & 0 & 0 \\
\hline Total & 18 & $100 \%$ & 18 & $100 \%$ & & \\
\hline
\end{tabular}

Berdasarkan tabel 2 menunjukan jenis kelamin responden terbanyak pada penelitian yaitu perempuan $(n=25 ; 69,44 \%)$, lebih dari $50 \%$ responden memiliki riwayat pendidikan SMA $(\mathrm{n}=20 ; 55,56 \%)$ dan seluruh responden pada penelitian ini mengkonsumsi obat $\mathrm{OHO}(\mathrm{n}=36 ; 100 \%)$.

Tabel. 3

Data Distribusi Responden Berdasarkan Kadar Gula Darah Sebelum dan Sesudah Puasa Ramadhan pada Kelompok Intervensi (n=18)

\begin{tabular}{lccccc}
\hline Variabel & N & Mean & SD & Min-Maks & 95\% CI \\
\hline Sebelum & 18 & 157.44 & 44.291 & $84-248$ & $135.42-179.47$ \\
Sesudah & 18 & 114.11 & 24.940 & $76-160$ & $101.17-126.51$ \\
\hline \multicolumn{7}{l}{ (sumber data primer tahun 2018) }
\end{tabular}

Berdasarkan tabel 3 menunjukan rata-rata kadar gula darah sebelum puasa ramadhan pada kelompok intervensi adalah 157.44 dengan standar deviasi 44.291. kadar gula darah terendah ialah 84 dan tertinggi ialah 248, Dari hasil estimasi interval dapat disimpulkan yakni $95 \%$ diyakini kadar gula darah sebelum puasa Ramadan responden penelitian pada kelompok intervensi ialah 135.42 sampai 179,47. Sedangkan rata-rata kadar gula darah sesudah puasa ramadhan pada kelompok intervensi adalah 114.11 dengan standar deviasi 24.940. kadar glukosa terendahnya ialah 76 dan tertingginya ialah 160. Dari hasil estimasi interval dapat disimpulkan yakni $95 \%$ diyakini kadar gula darah setelah puasa Ramadan responden penelitian pada kelompok intervensi ialah 101.17 sampai 126.51.

Tabel. 4

Data Distribusi Responden Berdasarkan Kadar Gula Darah Sebelum dan Sesudah Bulan Ramadhan pada Kelompok Kontrol $(\mathrm{n}=18)$

\begin{tabular}{llcccc}
\hline Variabel & N & Mean & SD & Min-Maks & $95 \%$ CI \\
\hline Sebelum & 18 & 140.39 & 40.680 & $86-228$ & $120.16-160.62$ \\
Sesudah & 18 & 129.94 & 30.966. & $91-201$ & $117.11-144.00$ \\
\hline
\end{tabular}

(sumber data primer tahun 2018)

Berdasarkan tabel 4 menunjukan rata-rata deskriftif kadar gula darah sebelum puasa ramadhan pada kelompok kontrol adalah 140.39 dengan standar deviasi 40.680. kadar gula darah terendah ialah 86 dan tertinggi ialah 228, Dari hasil estimasi interval dapat disimpulkan yakni 95\% diyakini kadar gula darah sebelum puasa Ramadan responden penelitian pada kelompok intervensi ialah 120.16 sampai 160,62. Sedangkan rata-rata kadar gula darah sesudah puasa ramadhan pada kelompok kontrol adalah 129.94 dengan standar deviasi 30.966. kadar glukosa terendahnya ialah 91 dan tertingginya ialah 201. Dari hasil estimasi interval dapat disimpulkan yakni $95 \%$ 
diyakini kadar gula darah setelah puasa Ramadan responden penelitian pada kelompok intervensi ialah 117.11 sampai 144.00.

\section{Analisis Bivariat}

Analisis bivariat menjelaskan pengaruh variabel independen terhadap variabel dependen, yaitu pengeruh puasa ramadhan terhadap penurunan kadar gula darah pada pasien diabetes tipe II di Puskesmas Kota Purwakarta Jawa Barat. Hasil analisis bivariat ini akan mengidetifikasi pengaruh kadar glukosa darah sebelum dan sesudah puasa ramadhan 1 bulan penuh pada pasien diabetes mellitus tipe II pada kelompok Intervensi dan kelompok Kontrol (tanpa berpuasa) dengan menggunakan T-Independen

Tabel. 5

Kadar Gula Darah Sebelum dan Setelah Puasa Ramadhan Selama 1 Bulan pada Kelompok Intervensi $(n=18)$

\begin{tabular}{lcccccc}
\hline Variablel & $\mathrm{N}$ & Mean & Std. deviasi & Std. error & $\mathrm{T}$ & p-Value \\
\hline Sebelum & 18 & 157,44 & 44,29 & 10,439 & \multirow{2}{*}{4,402} & \multirow{2}{*}{0.000} \\
Sesudah & 18 & 114,11 & 24,94 & 5,878 & & \\
\hline (sumber data primer tahun & 2018 )
\end{tabular}

Berdasarkan tabel 5 menunjukan bahwa nilai rata-rata kadar glukosa darah responden (kelompok intervensi) sebelum dilakukan puasa ramadhan adalah 157,44 $\mathrm{mg} / \mathrm{dL}$ dengan standar deviasi 44,29. Sedangkan nilai rata-rata pada responden (kelompok intervensi) setelah dilakukan puasa ramadhan adalah 114,11 mg/dL dengan standar deviasi 24,94. Hasil uji statistik t dependen menunjukan bahwa ada pengaruh yang bermakna antara kadar gula darah sebelum dilakukan puasa ramadhan dengan setelah dilakukannya puasa ramadhan pada kelompok intevensi $(\mathrm{p}=0,000),(\mathrm{t}=4,402)$, dengan nilai $\alpha=0,05$. Maka $\mathrm{p}<\alpha$ dimana Ho ditolak, yang artinya intervensi yang diberikan dalam bentuk menjalankan puasa ramadhan mempengaruhi kadar gula darah. Berdasarkan hasil tersebut, maka dapat disimpulkan bahwa ada pengaruh yang signifikan antara Puasa ramadhan dan terapi perawatan standar DM terhadap penurunan kadar gula darah pada pasien DM tipe II di Puskesmas Kota Purwakarta

Tabel. 6

Kadar Gula Darah Sebelum dan Setelah Bulan Ramadhan pada Kelompok Kontrol $(\mathrm{n}=18)$

\begin{tabular}{ccccccc}
\hline Variablel & N & Mean & $\begin{array}{c}\text { Std. } \\
\text { deviasi }\end{array}$ & Std. error & T & p-Value \\
\hline Kadar Gula Darah & 18 & 140,39 & 40,68 & 9,59 & & \\
sebelum & 18 & 129,94 & 30,96 & 6,79 & 2,14 & 0.047 \\
sesudah & 18 ) & & & &
\end{tabular}

Berdasarkan tabel 6 menunjukkan bahwa nilai rata-rata kadar glukosa darah responden (kelompok Kontrol) sebelum dilakukan puasa ramadhan adalah 140,39 $\mathrm{mg} / \mathrm{dL}$ dengan standar deviasi 40,68. Sedangkan nilai rata-rata pada responden (kelompok Kontrol) yang menjalankan terapi perawatan standar (tanpa puasa ramadhan) adalah 129,94 mg/dL dengan standar deviasi 30,96. Hasil uji statistik t dependen menunjukan bahwa ada pengaruh antara kadar gula darah sebelum dilakukan puasa ramadhan dengan setelah dilakukannya terapi perawatan standar pada kelompok kontrol 
$(\mathrm{p}=0,047),(\mathrm{t}=2,14)$, dengan nilai $\alpha=0,05$. Maka $\mathrm{p}<\alpha$ dimana Ho ditolak, yang artinya menjalani terapi perawatan yang sesuai dapat mempengaruhi kadar gula darah. Berdasarkan hasil tersebut, maka dapat disimpulkan bahwa adanya pengaruh pada terapi perawatan standar DM terhadap penurunan kadar gula darah pada pasien DM tipe II di Puskesmas Kota Purwakarta.

Pada variabel konsumsi obat tidak dilakukan uji homogenitas karena uji homogenitas dilakukan untuk menguji perbedaan antara kedua kelompok atau beberapa kelompok yang berbeda subjeknya atau sumber datanya. Sedangkan pada penelitian ini semua responden meminum obat $\mathrm{OHO}$, baik pada kelompok intervensi dan juga kelompok kontrol.Informan dalam penelitian ini berjumlah 5 (lima) orang ibu, dan yang pertama kali memiliki bayi preterm yang dirawat di ruang NICU dengan perawatan paling lama 50 hari.

Tabel. 7

Perbedaan Kadar Gula Darah Sebelum Setelah Puasa Ramadhan 1 Bulan pada Kelompok Intervensi dan Kelompok Kontrol

\begin{tabular}{ccccccc}
\hline Variablel & $\mathrm{N}$ & Mean & $\begin{array}{c}\text { Std. } \\
\text { deviasi }\end{array}$ & $\begin{array}{c}\text { Mean } \\
\text { Difference }\end{array}$ & T & p-Value \\
\hline Postest Intervensi & 18 & 114,11 & 24,9 & 20,22 & 2,15 & 0.039 \\
Postest Kontrol & 18 & 134,33 & 31,2 & &
\end{tabular}

Berdasarkan tabel 7 didapat bahwa selisih rata-rata kadar gula darah responden setelah melakukan puasa ramadhan pada kelompok intervensi dan kelompok kontrol yaitu $20,22 \mathrm{mg} / \mathrm{dL}$ dengan standar error 9,42. Uji statistik T-Independen menunjukkan nilai $(\mathrm{p}=0,039),(\mathrm{t}=2,147)$, sehingga dapat disimpulkan bahwa terdapat perbedaan yang bermakna kadar gula darah sesudah melakukan puasa ramadhan pada kelompok intervensi dan kelompok kontrol.

\section{PEMBAHASAN}

\section{Karakteristik Responden Umur}

Pasien diabetes mellitus yang menjadi responden penelitian baik pada kelompok intervensi dan kelompok kontrol di Puskesmas kota purwakarta jawabarat mempunyai umur antara 47 tahun sampai dengan 80 tahun. Dari hasil penelitan ini usia responden termasuk kedalam usia middle age sampai dengan old menurut Depkes.

Hasil ini sesuai dengan Mashudi (2011) yang mengatakan proses menua berlangsung setelah umur 30 tahun yang mengakibatkan perubahan anatomis, fisiologis dan biokimia. Perubahan dimulai dari tingkat sel berkelanjutan ke tingkat jaringan dan akhirnya pada tingkat organ yang mempengaruhi fungsi homeostatis. Komponen tubuh yang mengalami perubahan pada penelitian ini yaitu pada organ pancreas. Dalam pancreas terdapat sel Beta yang berfungsi sebagai penghasil insulin, jaringan target yang menghasilkan glukosa, system saraf dan hormone lainnya yang mempengaruhi kadar gula darah.

Perubahan anatomi, fisiologis dan biokimia yang terjadi pada DM tipe II mempengaruhi sel beta pancreas dalam menghasilkan insulin sehingga produksi insulin berkurang. Keadaan ini bersama dengan adanya resistensi insulin perifer, gangguan hepatic glucose production, dan menurunnya fungsi sel beta, yang akhirnya akan menuju kerusakan total sel b. menurut American Diabetes Assosiation (2008) 
menyatakan bahwa mula-mula timbul resistensi insulin, kemudian disusul oleh peningkatan insulin untuk mengkompensasi resistensi insulin agar gula darah tetap normal, lama kelamaan sel beta tidak sanggup lagi mengkompensasi resistensi insulin sehingga kadar gula darah meningkat dan fungus sel Beta semakin menurun (Suyono, 2013).

\section{Jenis Kelamin}

Jenis kelamin diabetes kelompok intervensi dan kelompok kontrol masing-masing sama banyak yakni 18 responden. Pada penelitian ini jenis kelamin responden di dominasi oleh jenis kelamin perempuan yaitu 13 orang perempuan pada kelompok intervensi dan 12 pada kelompok kontrol sisa nya adalah laki-laki.

Menurut Mashudi (2011) pada penderita diabetes mellitus tipe II belum diketahui secara pasti bahwa jenis kelamin itu mempengaruhi gula darah atau tidak. Namun dalam beberapa literatur dan juga penelitian sering kali jenis kelamin masuk kedalam karakteristik penderita diabetes.

Sedangkan sesuai dengan adanya pengaruh hormonal yang mengatur hormone seks yaitu adanya hormone androgen pada pria dan hormone estrogen pada perempuan yang belum terjadinya menapous, dapat berpengaruh terhadap pengaturan hormonal secara keseluruhan termasuk hormone insulin dan kekebalan tubuh (Smeltzer, 2014).

Asumsi peneliti meyakini bahwa pasien diabetes tipe II baik laki-laki maupun perempuan mempunyai resiko yang sama terhadap kejadian peningkatan atau penurunan kadar gula darah atau insiden terjadinya diabetes tipe II. Diketahui 5 pilar pengelolaan diabetes yaitu : edukasi, pengontrolan diit, olah raga, pengobatan diabetes, dan pemantauan kadar gula darah sendiri menjadi sangatlah penting yang harus dilakukan dalam kehidupan sehari-hari oleh pasein diabetes mellitus.

\section{Pendidikan}

Pada penelitian yang dilakukan oleh peneliti ditemukan pendidikan responden pada kelompok intervensi yakni pendidikan SMP 4 orang, pendidikan SMA 11 orang, pendidikan PT 3 orang. Sedangakn pendidikan pada kelompok kontrol didapatkan yakni pendidikan SMP 6 orang, pendidikan SMA 9 orang, Pendidikan PT 3 orang.hasil penelitian ini jumlah jenjang pendidikan responden terbanyak berada pada pendidikan SMA yakni pada kelompok intervensi berjumlah 20 responden pada kelompok intervensi dan kelompok kontrol.

Pendidikan merupakan serangkaian proses dalam mempengaruhi seseorang sehingga dapat menimbulkan prilaku. Semakin tinggi tingkat pendidikan semakin mudah untuk menerima informasi kesehatan. Sebaliknya semakin rendah tingkat pendidikan akan mengalami kesulitan dalam menerima informasi kesehatan sehingga mengakibatkan prilaku pasien dalam merawat penyakitnya berkurang sehingga beresiko untuk terjadinya komplikasi. Keyakinan seseorang terhadap kesehatan sebagian berbentuk variabel intelektual yang terdiri dari pengetahuan dan latarbelakang pendidikan. Latarbelakang pendidikan ini akan membentuk cara berfikir seseorang, termasuk membentuk kemampuan memahami factor-faktor yang berkaitan dengan penyakit (Potter \& Perry, 2008).

Penelitian Waluya (2008) di RSUP Dr. Hasan Sadikin Bandung memperoleh hasil distribusi responden berdasarkan tingkat pendidikan yang terbanyak adalah rendah. Hasil analisi bivariat menunjukan tidak ada hubungan antara tingkat pendidikn dengan kejadian rawat inap ulang pasien diabetes di RSUP Dr. Hasan Sadikin Bandung. 


\section{Konsumsi Obat}

Pada hasil penelitian ini ditemukan pada responden penderita diabetes tipe II baik pada kelompok intervensi dan kelompok kontrol semuanya mengkonsumsi obat atau terapi standar diabetes. Dalam penelitian ini semua responden kelompok intervensi dan kelompok kontrol yakni masing-masing 18 orang semuanya mengkonsumsi obat OHO.

Menurut Soegondo (2013) mekanisme kerja obat dalam menurunkan kadar gula darah antara lain dengan merangsang kelenjar pancreas untuk meningkatkan produksi insulin, menurunkan produksi gula dalam hepar, menghambat pencernaan karbohidrat sehingga dapat mengurangi apsorpsi gula darah dan merangsang reseptor. Menurut pendapat peneliti peneliti kedokteran/ farmakologi tentang effek atau pengaruh obat anti diabetes oral maupun insulin telah banyak dilakukan dengan metode eksperimen baik invivo maupun invitro.

Hasil penelitian ini sejalan dengan hasil penelitian yang dijelaskan oleh Dewi (2013) dalam penelitian ini menghasilkan temuan bahwa factor resiko prilaku yang berhubungan dengan kadar gula darah adalah sikap olahraga atau aktivitas fisik, sikap pengobatan, praktik diet atau pola makan, (praktik diet, olahraga, dan peraktik pengobatan).

\section{Perbedaan Kadar Gula Darah Sebelum dan Sesudah Puasa Ramadhan 1 Bulan pada Kelompok Intervensi Pasien Diabetes Mellitus Tipe II}

Pada penelitian ini menunjukan bahwa nilai rata-rata kadar glukosa darah responden (kelompok intervensi) sebelum dilakukan puasa ramadhan adalah 157,44 $\mathrm{mg} / \mathrm{dL}$ dengan standar deviasi 44,29. Sedangkan nilai rata-rata pada responden (kelompok intervensi) setelah dilakukan puasa ramadhan adalah $114,11 \mathrm{mg} / \mathrm{dL}$ dengan standar deviasi 24,94. Hasil uji statistik t dependen menunjukan bahwa ada pengaruh yang bermakna antara kadar gula darah sebelum dilakukan puasa ramadhan dengan setelah dilakukannya puasa ramadhan pada kelompok intevensi $(\mathrm{p}=0,000),(\mathrm{t}=4,402)$, dengan nilai $\alpha=0,05$. Maka intervensi yang diberikan dalam bentuk menjalankan puasa ramadhan mempengaruhi kadar gula darah. Berdasarkan hasil tersebut, maka dapat disimpulkan bahwa ada pengaruh yang signifikan antara Puasa ramadhan dan terapi perawatan standar DM terhadap penurunan kadar gula darah pada pasien DM tipe II di Puskesmas Kota Purwakarta.

Beberapa penelitian telah dilakukan oleh American Diabetes Association Scientific Session (2013) yang berkaitan dengan puasa telah mendapatkan hasil tentang manfaat puasa dan kesehatan tubuh memberikan efek yang baik, termasuk masalah kesehatan seperti diabetes tipe II. Seseorang yang mengalami gula darah yang tinggi kronis bisa menjauhi pada risiko terjadinya komplikasi dengan cara melakukan puasa secara bertahap untuk menstabilkan kadar gula darah pada tubuh.

Pada penelitian Justin et al., tahun 2016 yang meneliti 67 pelajar pria untuk dijadikan responden. Penelitian ini berdesign pre-test dan post-test. Pada tahap pertama responden akan di periksa kadar gula darah di minggu awal puasa ramadhan, untuk tahap dua dilakukan pada minggu keempat pada puasa ramadhan. Penelitian ini memberikan hasil bahwa puasa ramadhan pd individu uda yg sehat berdampak yang positif dalam pemeliharaan homeostatis gula darah. Pembatasan kalori selama bulan ramadhan itu cukup untuk meningkatkan sensitivitas insulin pada individu yang sehat.

Penelitian yang dilakukan Bener \& Yousafzai (2014) yang dilakukan di Qatar pada 1301 pasien diabetes diatas 18 tahun. Responden merupakan pasien rawat jalan Hamad General Hospital di Qatar. Hasil dari penelitian ini mengemukakan yakni 
puasa/shaum selama bulan ramadhan ada keterkaitan yang bermakna terhadap penurunan glukosa, HbA1C, profil lipid, dan tekanan darah. Pasien diabetes Islam dapat berpuasa selama bulan ramadhan dan dapat bermanfaat untuk kesehatan mereka, tentunya setelah berkonsultasi dengan petugas kesehatan.

Berdasarkan analisi peneliti dari hasil penelitian yang dilakukan dan ditunjang oleh beberapa hasil penelitian peneliti berasumsi bahwa puasa ramadhan aman dilakukan oleh pasien penderita diabetes mellitus tipe II. Tentunya hal ini dilakukan dengan selalu memperhatian kondisi pasien penderita diabetes itu sendiri. Pasien yang dapat melakukan puasa ramadhan tentunya yang termasuk kedalam gologan pasien beresiko sedang saja.

Peneliti juga berasusmi bahwa puasa ini dapat menjadi terapi non farmakologis sebagai pengolaan diet pada penderita diabetes. Pada saat berpuasa kadar glukosa darah akan turun sehingga menyebabkan penurunan sekresi insulin, yang kemudian mengakibatkan peningkatan kerja hormon kontra insulin yakni glucagon dan katekolamin yang mengsilkan pemecahan glikogen. Setelah beberapa jam berpuasa cadangan glikogen dalam tubuh akan berkurang.

\section{Perbedaan Kadar Gula Darah Sebelum dan Sesudah Bulan Ramadhan pada Kelompok Kontrol Pasien Diabetes Mellitus Tipe II}

Pada penelitian ini menunjukan bahwa nilai rata-rata kadar glukosa darah responden (kelompok Kontrol) sebelum dilakukan puasa ramadhan adalah 140,39 $\mathrm{mg} / \mathrm{dL}$ dengan standar deviasi 40,68. Sedangkan nilai rata-rata pada responden (kelompok Kontrol) yang menjalankan terapi perawatan standar (tanpa puasa ramadhan) adalah 129,94 mg/dL dengan standar deviasi 30,96. Hasil uji statistik t dependen menunjukan bahwa ada pengaruh antara kadar gula darah sebelum dilakukan puasa ramadhan dengan setelah dilakukannya terapi perawatan standar pada kelompok kontrol $(\mathrm{p}=0,047),(\mathrm{t}=2,14)$, dengan nilai $\alpha=0,05$. Sehingga menjalani terapi perawatan yang sesuai dapat mempengaruhi kadar gula darah. Berdasarkan hasil tersebut, maka dapat disimpulkan bahwa adanya pengaruh pada terapi perawatan standar DM terhadap penurunan kadar gula darah pada pasien DM tipe II di Puskesmas Kota Purwakarta. Hal ini tidak sejalan dengan Penelitian yang di lakukan oleh Fatmaningrum (2017) yang menyatakan bahwa tidak adanya pengaruh yang signifikan pada kelompok control.

Menurut asumsi peneliti terdapat beberapa ketidaksamaan pada penelitian tersebut yang mengakibatkan keetidaksejalanan antara penelitian peneliti dengan penelitan yang lain. Kadar gula darah dapat saya di pengaruhi oleh factor internal dan eksternal. Jika pada kelompok control tidak ada pengaruh bisa saja diakibatkan oleh kepatuhan minum obat pada pasien tidak sesuai. Dan juga kesadaran seseorang terkait dengan kesehatan diri sendiri yang kurang baik sehingga mengabaikan kestabilan gula darah.

Pengelolaan penderita DM memerlukan keaktifan dari penderita sendiri, keluarga dan masyarakat. Pada dasarnya tim kesehatan hanya mendampingi pasien dalam perubahan pola hidup sehat. Dalam proses perubahan prilaku dibutuhkan edukasi/pendidikan yang berkesinambungan dan upaya peningkatan motivasi. Dalam melakukan pengontrolan gula darah dapat dilakukan secara mandiri setelah mendapatkan pelatihan khusus.Pendidikan kesehatan diberikan untuk peningkatan kualitas hidup, dan perlu dilakukan sebagai upaya pencegahan dan pengelolaan DM secara holistik. Pendidikan kesehatan/edukasi dapat dipromosikan kepada penderita DM meliputi pemahaman terkait: Riwayat penyakit DM, Manfaat pengontrolan dan pengendalian DM secara berkesinambungan, masalah DM dan factor resikonya, 
Penatalaksanaan pengobatan \& non farmakologis dan target pengobatan, Komunikasian diet, aktivitas fisik, \& OHO/insulin serta medikasi lainya, Menagani keadaan darurat contohnya keadaan nyeri atau hipoglikemy, Olah raga fisik yang dilakukan secara teratur, permasalah spesifik yang umumnya dihadapi (misalnya; hiperglikemi pada masa kandungan).

Menurut Black \& Hawks (2014) Seseorang diabetes penting menjaga keteraturan pola makan, jenis dan porsi makanan, terutama harus ditekankan pada penderita DM yang mengkonsumsi obat seperti OHO dan Insulin. Komposisi makanan yang seimbang dan tersetandar dalam hal kecukupan gizi yang baik yakni, kebutuhan karbohidrat 4560000, protein 10-200, lemak 20-2500. Kalori harus di sesuaikan dengan status gizi, umur, pertumbuhan, dan kegiatan aktivitas fisik untuk mempertahankan dan mencapai BB ideal.(Waspadji dalam Soegondo et al., 2013).

Menurut PERKENI (2011) Terapi farmakologi dikonsumsi bersamaan dengan pengelolaan makanan dan pergerakan fisik(pola hidup sehat). Intervensi farmakologi dipertimbangkan ketika pasien sulit mengontor kadar guladarah dengan olahraga dan diet. Terapi farmakologi antara lain yaitu obat oral dan suntikan : Obat hipoglikemik oral (OHO). Obat Hypoglikemi oral terdapat 5 klompok berdasarkan cara kerjanya: stimulasi sekresi insulin : sulfonilurea dan glinide, Peningkat sensitivitas terhadap insuln : metformin \& tiazolidindion, Penghambat glukoneogenesis : metformind, Penghambat absorpsi gula darah : memperlambat glukosidase alfa, DPP-IV inhibitor

\section{Perbedaan Kadar Gula Darah Sesudah Melakukan Puasa Ramadhan antara Kelompok Intervensi dan Kelompok Kontrol}

Hasil penelitian yang diakukan oleh peneliti diketahui bahwa selisih rata-rata kadar gula darah responden setelah melakukan puasa ramadhan pada kelompok intervensi dan kelompok kontrol yaitu 20,22 mg/dL dengan standar error 9,42. Uji statistik T-Independen didapatkan menunjukkan nilai $(\mathrm{p}=0,039),(\mathrm{t}=2,147)$, dengan $\alpha=0,05$, sehingga dapat disimpulkan bahwa terdapat perbedaan yang bermakna kadar gula darah sesudah melakukan puasa ramadhan pada kelompok intervensi dan kelompok kontrol.

Sedangkan riset yang dilaksanakan Bener \& Yousafzai (2014) memperlihatkan bahwwa kadar glukosa darah pada penderita diabetes melitus yang melakukan puasa selama bulan Ramadhan (1 bulan) mengalami penurunan secara signifikan dibandingkan dengan sebelum Ramadhan.

Berdasarkan analisi peneliti dari hasil penelitian yang dilakukan dan ditunjang oleh beberapa hasil penelitian peneliti berasumsi bahwa puasa ramadhan memberikan pengaruh yang signifikan terdapak kadar gula darah dikarenakan menurut PERKENI (2015) pada saat berpuasa terjadi penurunan sekresi insulin yang menyebabkan kadar gula darah menjadi turun, yang kemudian mengakibat kan peningkatan hormone kerja dari hormone kontra insulin yakni glucagon dan katekolamin yang menghasilkan pemecahan glikogen. Setelah beberapa jam berpuasa cadangan glikogen mulai berkurang, akibat dari berkurangnya insulin dalam sirkulasi inilah akan menimbulkan asam lipid. Asam lemak bisa di pecah untuk menghasilkan energy (Smeltzer \& Bare, 2014)

Selain itu pada hasil penelitian kelompok control juga dapat mempengaruhi kadar gula darah dalam tubuh. Menurut peneliti penurunan tersebut diakibakan oleh control individu terhadap gula darah sangat baik selain dari pola makan yang dimodifikasi menjadi puasa juga dapat dilakukan dengan cara lain misalnya,aktivitas fisik, 
pengetahuan serta pengobatan dan control gula darah yang rutin.

Menurut Black \& Hawks (2014) Seseorang diabetes penting menjaga keteraturan pola makan, jenis dan porsi makanan, terutama harus ditekankan pada penderita DM yang mengkonsumsi obat seperti OHO dan Insulin.

Menurut Soegondo et al., (2013) secara keseluruhan bahwa pasien DM membutuhkan pengobatan untuk menstabilkan gula darahnya bagi penderita yang sudah tidak dapat terkontrol gula darahnya. Selanjutnya dapat diberikan intervensi lebih lanjut

\section{SIMPULAN}

Berdasarkan hasil penelitian dan pembahasan pada penelitian ini dapat beberapa hal, yaitu kadar gula darah sebelum dan sesudah puasa ramadhan pada kelompok intervensi mengalami penurunan. Kadar gula darah pada kelompok kontrol yang tidak melakukan Puasa Ramadhan mengalami kenaikan namun ada beberapa responden mengalami penurunan kadar gula darah. Sehingga dapat disimpulkan bahwa Puasa Ramadhan dapat berpengaruh terhadap penurunan kadar gula darah pada penderita diabetes mellitus tipe II.

\section{SARAN}

Direkomendasikan kepada pihak-pihak yang terkait dengan penatalaksaan pada Penderita diabetes Mellitus tipe II adalah:

Disarankan pada penderita diabetes mellitus tipe II dengan kadar glukosa darah yang tidak terkontrol untuk menjalankan puasa khususnya ramadhan guna untuk membantu mengontrol kadar gula darah dalam batas yang normal. Disamping itu diharapkan pada penderita diabetes mellitus tipe II untuk melakukan pengontrolan atau pemeriksaan kadar gula darah secara rutin sehingga disamping menjalani puasa gula darah dapat terkontol dengan baik.

Perawat dapat memberikan edukasi kepada pasien tentang manfaat puasa ramadhan pada pasien diabetes tipe II, berkerja sama dengan tim kesehatan lain dalam memberikan metode diet untuk dapat mengontrol kadar gula darah. Perawat dapat meningkatkan motivasi, dukungan dan pengetahuan tentang manfaat puasa khususnya puasa ramadhan terhadap penderita diabetes mellitus tipe II. Serta Perlunya memasukan materi tentang diet dan manajemen non farmakologis dalam materi penbelajaan terkait penyakit sehingga mampu memberikan asuhan keperawatan secara komperhensif kepada penderita DM tipe II

Peneliti ini dapat digunakan sebagai dasar untuk mengembangkan penelitian selanjutnya mengenai pengaruh puasa ramadhan terhadap penderita diabetes mellitus tipe II. Selain itu Penelitian selanjutnya dapat meneliti pengaruh puasa ramadhan terhadap penurunan kadar gula darah pada pasien diabetes mellitus tipe II dengan sampel yang lebih besar dan metode yang berbeda. 


\section{DAFTAR PUSTAKA}

ADA (American Diabetes Association). (2008). Diabetes Management Guidlines, www.ndei.org/ADA

ADA (American Diabetes Association). (2013). Diabetes Management Guidlines, www.ndei.org/ADA

Bare, B., \& Smeltzer, S. (2010). Buku Ajar Keperawatan Medikal Bedah. Jakarta: EGC

Bener, A., \& Yousafzai, M. T. (2014). Effect of Ramadan Fasting on Diabetes Mellitus: a Population-Based Study in Qatar. Journal of the Egyptian Public Health Association, 48 (2): 47-52. https://journals.lww.com/ephaj/Fulltext/ 2014/08000

Black, J., \& Hawks, J. (2014). Keperawatan Medikal Bedah : Manajemen Klinis untuk Hasil yang Diharapkan. Jakarta: Salemba

Dewi, R. P. (2013). Faktor Risiko Perilaku yang Berhubungan dengan Kadar Gula Darah pada Penderita Diabetes Melitus Tipe 2 di RSUD Kabupaten Karanganyar, Jurnal Kesehatan Masyarakat FKM Undip, 2(1), 1-11

Fatmaningrum, F. (2017). Pengaruh Puasa Sunnah Senin Kamis terhadap Kadar Glukosa Darah pada Pasien Diabetes Melitus Tipe II di Puskesmas Bantul, Universitas Aisyiyah Yogyakarta, 1-9, http://digilib.unisayogya.ac.id/2531/1/ http://digilib.unisayogya.ac.id/2531/1/naskah publikasi

IDF (International Diabetes Federation). (2013). IDF Diabetes Atlas 6th edition, http://www. diabetes atlas.org/

IDF (International Diabetes Federation). (2017). IDF Diabetic Atlas 8th, http://www. diabetes atlas.org/

Justin, V., \& Gnaou, E. A. (2016). Effects of Ramadhan Fasting on Glucose Homeostasis and Adiponectin Levels in Healthy Adult Males. Journal of Diabetes \& Metabolic Disorders, $14, \quad$ 14-55. https://www.ncbi.nlm.nih.gov/pmc/articles/PMC4494190

Kementrian Kesehatan Republik Indonesia. (2013). Profil Kesehatan Indonesia; Healty Statistics, http://www.Kemenkes.go.id

Liza, L. (2009). Puasa dalam Kajian Islam dan Kesehatan, Dinkes Kabupaten cirebon. 1-14. http. www.Scribed.com/doc/6224538

Mashudi, M. (2011). Pengaruh Progressive Muscle Relaxation terhadap Kadar Glukosa Darah Pasien Diabetes Melitus Tipe 2 di RSUD Raden Matteher Jambi. Depok: Tesis FIK UI. http://lontar .ui.ac.id/file?file=digital/202816987\%.20Mashudi.pdf

Perkeni. (2011). Konsensus Pengelolaan dan Pencegahan Diabetes Melitus Tipe II di Indonesia. Jakarta: PB PERKENI

Perkeni. (2015). Pengelolaan dan Pencegahan Diabetes Mellitus Tipe II di Indonesia; Panduan Penatalaksanaan DM Tipe II pada Individu Dewasa di Bulan Ramadan. http.www.pbperkeni.or.id

Potter, A., \& Perry, A. G. (2006). Buku Ajar Fundamental Keperawatan: Konsep, Proses, Dan Praktik, Edisi 4, Volume. 2. Jakarta: EGC

Riskesdas. (2013). Badan Penelitian Pengembangan Kesehatan Kementerian Kesehatan RI (2013). Riset Kesehatan Daerah. Jakarta: Riskesdas: 2013

Smeltzer, S., \& Bare, B. (2014). Keperawatan Medikal Bedah Brunner \& Suddart ed 12. Jakarta: EGC

Soegondo, S. (2008). Hidup Secara Mandiri dengan Diabetes Mellitus Kencing Manis Sakit Gula. Jakarta: FK UI 
Soegondo, S. (2013). Penatalaksanaan Diabetes Melitus Terpadu sebagai Panduan Penatalaksanaan Diabetes Melitus bagi Dokter maupun Edukator. Jakarta: Balai Penerbit FKUI

Sutedjo, A. (2010). 5 Strategi Penderita Diabetes Mellitus Berusia Panjang. Jogyakarta: Kanisius

Suyono, S. (2013). Kecendrungan Peningkatan Jumlah Penyandang Diabetes. Jakarta: FKUI

Waluya, N. A. (2008). Hubungan Kepatuhan Pasien dengan Kejadian Ulkus Diabetik dalam Konteks Asuhan Keperawatan Pasien Diabetes Melitus di RSUP Dr. Hasan Sadikin Bandung. Skripsi. Universitas Indonesia

Yosephine, Y. (2002). Pengaruh Puasa selama Ramadan terhadap Status Klinik Penderita Diabetes Melitus Tipe 2. www.univmed.org/wpcontent/uploads/2011/02/Yosephine.pdf 